\title{
Linear parameter varying sensorless torque control for singularly perturbed induction motor with torque and flux observers
}

\author{
Dalila Khamari $^{1} \cdot$ Idriss Benlaloui $^{1,2} \cdot$ Sabir Ouchen $^{3}\left(\right.$ Abdesslem Makouf $^{1} \cdot$ Larbi Chrifi Alaoui $^{4}$
}

Received: 6 February 2020 / Accepted: 17 August 2020 / Published online: 1 September 2020

(c) The Author(s) 2020

\begin{abstract}
In this paper, a new approach being different from the concept of DTC and IFOC for a robust torque control design for induction motor is addressed. The design is based on the framework of singularly perturbed system theory and linear varying parameter systems. In these systems, the rotor flux is considered to be a time-varying parameter in order to guarantee a robust torque control with LPV flux observer with respect to the speed and resistance variations. In fact, this observer is designed to estimate the rotor flux as well as an MRAS observer is introduced to estimate the mechanical speed and rotor resistance. The main feature of this proposed structure is the enhancement of robustness with flux, speed and rotor resistance variation. This improvement leads to a considerable decrease of the torque ripples and ensures the stability for the entire operating range. The obtained simulations and experimental results are used to validate the effectiveness of the proposed control strategy.
\end{abstract}

Keywords $H_{\infty}$ LPV controller $\cdot$ Singularly perturbed system $\cdot$ LMI $\cdot$ MRAS observer $\cdot$ Induction motor

\section{Abbreviations}

$\Omega \quad$ Rotor speed (rd/s)

$\omega_{s} \quad$ Stator current frequency $(\mathrm{rd} / \mathrm{s})$

$\omega r \quad$ Induced rotor current frequency $(\mathrm{rd} / \mathrm{s})$

$\omega c \quad$ Injected rotor current frequency $(\mathrm{rd} / \mathrm{s})$

J In Inertia

$f \quad$ Coefficient of viscous

$C_{\mathrm{m}} \quad$ Maximal electromagnetic torque

$\sim \quad$ Symbol indicating measured value

1 Symbol indicating the estimated value

Sabir Ouchen

sabir.ouchen.dz@ieee.org

Dalila Khamari

khamari.dalila@yahoo.com

Idriss Benlaloui

idrissb88@yahoo.fr

Larbi Chrifi Alaoui

larbi.alaoui@u-picardie.fr

1 LSPIE Laboratory, Electrical Engineering Department, University of Batna 2, Batna, Algeria

2 Université 8 mai 1945, Guelma, Algeria

3 PowerElectronics and Electrical Drives Laboratory, Aalen University, Aalen, Germany

4 University of Picardie Jules Verne, Cuffies, France
* Symbol indicating the command value

IM Induction motor

MRAS Model reference adaptive system

LPV Linear parameter varying

$s, r \quad$ Rotor and stator indices

$d, q$ Direct and quadrate indices for orthogonal components

${ }^{-} x \quad$ Variable complex such as: ${ }^{-} x=\_e\left[{ }^{-} x\right]+j \cdot{ }^{-} m\left[{ }^{-} x\right]$ with $j^{2}=-1$

${ }^{-} x \quad$ Represents either a voltage as ${ }^{-} u$, a current as ${ }^{-} i$ or a flux as ${ }^{-} \phi$

${ }^{-} x * \quad$ Complex conjugate

$R s, R r \quad$ Stator and rotor resistances

$L s, L r \quad$ Stator and rotor inductances

$\tau_{\mathrm{s}}, \tau_{\mathrm{r}} \quad$ Stator and rotor time-constants $\left(\tau_{\mathrm{sr}}=L s, r / R s, r\right)$

$\sigma \quad$ Leakage flux total coefficient $(\sigma=1-M 2 / L r L s)$

$M \quad$ Mutual inductance

$P \quad$ Number of pole pairs

$\omega \quad$ Mechanical rotor frequency $(\mathrm{rd} / \mathrm{s})$

\section{Introduction}

Research interest in induction motor sensor less drives has grown significantly over the past years due to their advantages such as mechanical robustness, simple construction 
and low maintenance. Since the dynamic performances of such machine satisfy the majority of industrial applications, the notion of robustness is then considered as an additional objective of the machines control. Thus, field oriented control (FOC) and direct torque control (DTC) are the most wellknown control structures used in AC-drives [1, 2]. However, the major disadvantage of the FOC control is the sensitivity to parameters variation, the inaccuracy on the rotor flux and rotor speeds estimation especially at low speed region. This drawback causes an uncertainty on the knowledge of the angular position of the referential $(d, q)$. Additionally, vector control generates flux amplitudes less than those attainable with the given DC bus voltage. Therefore, the peak torque capacity of the drive is decreasing with the power losses increase. For the IM drives undergo gradual torque changes weakened field, the flux must be further reduced and the voltage margin must be increased in order to avoid saturation of the current loops. On the other hand, DTC technique allows a fast and accurate torque response without the complex flux orientation bloc. In the scientific literature, there are several DTC-based structures such as direct self-control [3], vector selection strategy with switching table $[4,5]$, and deadbeat control strategies [6]. However, their switching frequency varies according to the motor speed and the hysteresis bands of torque and flux comparators. In turn, this results in a large torque ripple unless a very short sampling time is provided [7]. Also, the most DTC concepts are based on kind of inversion of the IM model [8, 9] and therefore they are sensitive to parameters variation. A comparative analysis of the IFOC and DTC methods, taking into account the effects of parameters variation in the estimation of the rotor flux [7], as well as the characteristics of the motor and their performance is provided [10-12].

In this paper, a new approach is proposed for the torque control of an induction motor where the rotor flux is considered, as a varying parameter working in all the operating range. This approach contributes to:

i. A robustness modeling defined by a singularly perturbed nonlinear model [13] (decomposition of the system model in two subsystems) of the induction motor, where the axis d of the referential $(d, q)$ is collinear at all times with the vector linked to the stator current. This deals with $i_{s q}=0$ and $\frac{d i_{s q}}{d t}=0$ with $i_{s d} \geq 0$ or the condition $i_{s d} \geq 0$ means that the axis $\mathrm{d}$ is oriented in the direction of the stator current vector $i_{\text {sd }}$ and the choice to orient the reference work frame on the stator current was guided by the following motivations:

First motivation Robustness with respect to stator current sensors and in this case, the closed-loop control of the working referential orientation is naturally robust since the regulation of the component $q$ is realized from a measurement and not from an estimation, Second motivation Robustness with respect of the inaccuracy on the speed measurement where the angular position of the referential $(d, q)$ is known at all times from the measurement of the components $\left(i_{s \alpha}, i_{s \beta}\right)$ it follows that the imprecision on the measurement of the rotor speed $(\Omega)$ does not represent a disturbance for the reference $(d, q)$ orientation. This naturally leads to consider a speed sensor less control. Note that this choice provides a simple and efficient solution to the main robustness problem of IFOC.

ii. The temporal evolution of $\phi_{\mathrm{rd}}$ is directly linked to the variation of the operating point of the slow subsystem defined by the torque amplitude $\left(C_{\mathrm{m}}\right)$. In this case, the dynamic controllers based on the LPV system theory taking into account the variation of the rotor flux, rotor speed and rotor resistance, respectively, for torque control and flux estimation [16-18] is an alternative to robust control with fixed controller parameters in induction motor control [20].

The LPV modeling of the electromagnetic torque allowed to have a dynamic controlled only by the slip, it is independent of the rotation speed $(\Omega)$ and it is perturbed by the term $\left(\frac{\phi_{r}^{* 2}}{\phi_{r d}^{2}(t)}\right)$.

The major advantage of this method is the power of mathematical tools computation based on linear matrix inequality with convex optimization [14] allowing the on-line computation, the very fast adaptation of the parameters in response to sudden variations of the operating point. Also, the parameters of the controller are modified in open loop without return of the system performance in closed loop as proven by several works concerning the robust LPV control of the induction motor.

In order to get the rotor speed and torque estimation, an MRAS observer algorithm is developed [21-24]. This later is chosen for its design simplicity and ease implementation.

This paper is organized as follows: The second section gives a brief review on singularly perturbed systems theory. The description of singularly perturbed Park model of the induction model is given in Sect. 3. In Sects. 4 and 5, the reformulation of the electromagnetic torque in the singularly perturbed system and the synthesis of the LPV controller and LPV flux observer with stability analysis are widely developed, the design of the speed and torque estimator by the MRAS method are explained in details. Finally, simulations and experimental results of LPV control are discussed in Sects. 6 and 7 . 


\section{Recalls on singular perturbation}

Let's consider the LTI singularly perturbed systems defined by the state representation:

$$
\left\{\begin{array}{l}
\dot{x}=A_{11} x+A_{12} z, \quad x\left(t_{0}\right)=x_{0} \\
\varepsilon \dot{x}=A_{21} x+A_{22} z+B_{2} u_{c}, \quad z\left(t_{0}\right)=z_{0}
\end{array}\right.
$$

with $x \in R^{n}, z \in R^{m}, u \in R^{r}, x$ is the slow variable, $z$ is the fast variable, $u_{c}$ is the control input and $\varepsilon$ is a small parameter.

Note that only the fast mode is controlled by the input $u_{c}$. These restrictions simplify the study and will allow transposing directly the obtained results of system (1) to the Park model.

Generally, the $u_{c}$ command associated with the singular perturbation methodology is decomposed as follows:

$u_{\mathrm{c}}=u_{\mathrm{f}}+u_{\mathrm{s}}$

Or when relation (2) is applied to system (1), $\mathrm{u}_{\mathrm{f}}$ represents the fast part control and $\mathrm{u}_{\mathrm{s}}$ the slow part control. These results yield to a composite state-feedback control for the original system (1).

According to the Tihonov theorem applied to linear systems, the two-time scale approximation of system (1) results in:

$\dot{\bar{x}}=\left(A_{11}+A_{12} A_{22}^{-1} A_{21}\right) \bar{x}-A_{12} A_{22}^{-1} B_{2} u_{s}$

where $O(\varepsilon)$ represents the approximation error on the slow states when $\varepsilon \rightarrow 0$ after a short transitory period defined by $\eta\left(t_{f}\right)$. The states $(\bar{x}, \bar{z})$ are then a good approximation of the states $(\bar{x}, \bar{z})$.By setting $\varepsilon=0$, if $A_{22}$ is stable and invertible, we would obtain the unique solution of the quasi steady state relating to the fast mode:

$\bar{z}=-A_{22}^{-1}\left(A_{21} \bar{x}+B_{2} u_{s}\right)$

By introducing relation (4) in the initial model (1), the slow model becomes.

$\dot{\bar{x}}=\left(A_{11}+A_{12} A_{22}^{-1} A_{21}\right) \bar{x}-A_{12} A_{22}^{-1} B_{2} u_{s}$

The slow subsystem can be closed by a state feedback as follows:

$u_{\mathrm{s}}=-k_{\mathrm{s}} \bar{x}$

In the transient state and according to relation (3), the variable is considered as the error between state $\mathrm{z}$ and its quasi-state value $\bar{z}$ :

$\eta=z-\bar{z}$
The dynamics of $\eta$ in the time scale $t$ is written as follows:

$\varepsilon \frac{d(\eta)}{d t}=A_{21} x+A_{22}(\eta+\bar{z})+B_{2}\left(u_{s}+u_{f}\right)-\varepsilon \dot{\bar{z}}$

By deriving Eq. (4) and considering $u_{s}=0$, we obtain $\varepsilon \dot{\bar{z}}=$ 0 .Then, one can deduce the following relation:

$\varepsilon \frac{\mathrm{d}(\eta)}{\mathrm{d} t}=A_{21} x+A_{22} \bar{z}+A_{22}(\eta)+B_{2} u_{\mathrm{s}}+B_{2} u_{\mathrm{f}}$

With:

$A_{21} x+A_{22} \bar{z}+B_{2} u_{\mathrm{s}}=0$

The term, which cancels out, results from the slow dynamics control. The reduced order fast system is then expressed by:

$\varepsilon \frac{\mathrm{d}(\eta(t))}{\mathrm{d} t}=A_{22}(\eta(t))+B_{2} u_{\mathrm{f}}(t)$

The above relationship defined in the dilated time scale $t_{f}$ (fast time scale) is still known by(boundary layer) and by transforming the slow time scale, $t_{\mathrm{f}}=\frac{t-t_{0}}{\varepsilon} 0$, we can write:

$\varepsilon \frac{\mathrm{d}(\eta(t))}{\mathrm{d} t}=A_{22} \eta\left(\varepsilon t_{\mathrm{f}}+t_{0}\right)+B_{2} u_{\mathrm{f}}\left(\varepsilon t_{\mathrm{f}}+t_{0}\right)$

With:

$\eta(0)=z\left(t_{0}\right)+\bar{z}\left(t_{0}\right)$

In order to reduce the transient state of the fast mode and consequently accelerate the convergence of $z$ to $\bar{z}$, the natural dynamics of $\eta$ must be increased by the fast component $u_{\mathrm{f}^{-}}$ based feedback such that:

$u_{\mathrm{r}}=-k_{\mathrm{f}} \eta$

Through the feedback looping, the decomposition of system (1) into two distinct time scales is even more reinforced since the gain $k_{\mathrm{f}}$ is important. The feedback loops (6) and (12) are applied to each subsystem of reduced order such that the initial system (1) is looped by a composed state feedback:

$u_{\mathrm{c}}=u_{\mathrm{f}}+u_{\mathrm{s}}$

\section{Singularly perturbed park model of induction motor}

If the induction motor is powered by a voltage source, the components $V_{\mathrm{sd}}$ and $V_{\mathrm{sq}}$ are then taken as control variables and if the components $i_{\mathrm{sd}}$ and $i_{\mathrm{sq}}$ of the stator current and 
rotor fluxes $\phi_{\mathrm{rd}}$ and $\phi_{\mathrm{rq}}$ are selected as the state variables, the Park model is expressed by:

$$
\left\{\begin{array}{l}
\dot{i}_{\mathrm{sd}}=-\gamma i_{\mathrm{sd}}+\omega_{\mathrm{s}} i_{\mathrm{sq}}+\frac{k}{\tau_{\mathrm{r}}} \phi_{\mathrm{rd}}+k p \Omega \phi_{\mathrm{rq}}+\frac{1}{\sigma L_{\mathrm{S}}} V_{\mathrm{sd}} \\
\dot{i}_{\mathrm{sq}}=-\omega_{\mathrm{s}} i_{\mathrm{sd}}-\gamma i_{\mathrm{sq}}-k p \Omega \phi_{\mathrm{rd}}+\frac{k}{\tau_{\mathrm{r}}} \phi_{\mathrm{rq}}+\frac{1}{\sigma L_{\mathrm{s}}} V_{\mathrm{sq}} \\
\dot{\phi}_{\mathrm{rd}}=\frac{M}{\tau_{\mathrm{r}}} i_{\mathrm{sd}}-\frac{1}{\tau_{\mathrm{r}}} \phi_{\mathrm{rd}}-p \Omega \phi_{\mathrm{rq}}+\omega_{\mathrm{s}} \phi_{\mathrm{rq}} \\
\dot{\phi}_{\mathrm{rq}}=\frac{M}{\tau_{\mathrm{r}}} i_{\mathrm{sq}}+p \Omega \phi_{\mathrm{rd}}-\omega_{\mathrm{s}}-\phi_{\mathrm{rd}} \frac{1}{\tau_{\mathrm{r}}} \phi_{\mathrm{rq}}
\end{array}\right.
$$

Where:

$\sigma=1-\frac{M^{2}}{L_{\mathrm{s}} L_{\mathrm{r}}}, \quad \gamma=\frac{R_{\mathrm{S}}}{\sigma L_{\mathrm{s}}}+\frac{R_{\mathrm{r}} M^{2}}{\sigma L_{\mathrm{s}} L_{\mathrm{r}}^{2}}, \quad \tau_{\mathrm{r}}=\frac{L_{r}}{R_{\mathrm{r}}}, \quad k=\frac{M}{\sigma L_{\mathrm{s}} L_{\mathrm{r}}}$

The electromagnetic torque equation is given by:

$C_{\mathrm{m}}=p \frac{M}{L_{\mathrm{r}}}\left[i_{\mathrm{sq}} \phi_{\mathrm{rd}}-\phi_{\mathrm{rq}} i_{\mathrm{sd}}\right]$

Given classical mechanical dynamics, by introducing relation (15), we obtain:

$J \dot{\Omega}=p \frac{M}{L_{\mathrm{r}}}\left[\phi_{\mathrm{rd}} i_{\mathrm{sq}}-\phi_{\mathrm{rq}} i_{\mathrm{sd}}\right]+C_{\mathrm{o}}+k_{1} \Omega+k_{2} \Omega^{2}$

Therefore, by setting:

$x=\left(\phi_{\mathrm{rd}}, \phi_{\mathrm{rq}}, \boldsymbol{\Omega}\right)^{T} \quad$ slow subsystem

$z=\left(i_{\mathrm{sd}}, i_{\mathrm{sq}}\right)^{T}$ fast subsystem

$u=\left(v_{\mathrm{sd}}, v_{\mathrm{sq}}\right)^{T}$ control variables

$\boldsymbol{\varepsilon}=\sigma=1-\frac{M^{2}}{L_{\mathrm{s}} L_{\mathrm{r}}}$.

The scope of this work is restricted to the slow system control only.

\subsection{Slow sub system}

Under the standard simplifying hypotheses, the dynamic singularly perturbed equation with the oriented current component $i_{\mathrm{sq}}=0$ can be expressed by:

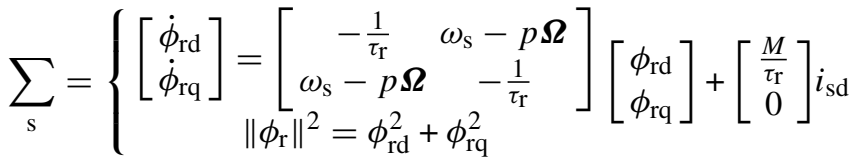

As can be observed that the system output is nonlinear and the term $\left(\omega_{\mathrm{s}}-p \Omega\right)$ occur as the control variable in state Eq. (15). The slow subsystem $\Sigma_{\mathrm{s}}$ can be used for controlling both flux and torque.

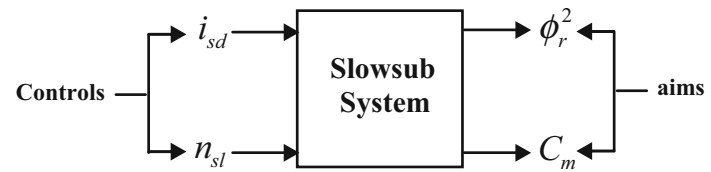

Fig. 1 Slow subsystem control structure

The flux dynamic can be expressed by the slow subsystem $\Sigma_{\mathrm{s}}$ as follows:

$$
\begin{aligned}
{\left[\phi_{\mathrm{rd}}, \phi_{\mathrm{rq}}\right]\left[\begin{array}{c}
\dot{\phi}_{\mathrm{rd}} \\
\dot{\phi}_{\mathrm{rd}}
\end{array}\right]=} & {\left[\phi_{\mathrm{rd}}, \phi_{\mathrm{rq}}\right]\left[\begin{array}{cc}
-\frac{1}{\tau_{\mathrm{r}}} & \omega_{\mathrm{s}}-p \boldsymbol{\Omega} \\
\omega_{\mathrm{s}}-p \boldsymbol{\Omega} & -\frac{1}{\tau_{\mathrm{r}}}
\end{array}\right]\left[\begin{array}{c}
\phi_{\mathrm{rd}} \\
\phi_{\mathrm{rq}}
\end{array}\right] } \\
& +\left[\phi_{\mathrm{rd}}, \phi_{\mathrm{rq}}\right]\left(\begin{array}{c}
\frac{M}{\tau_{\mathrm{r}}} \\
0
\end{array}\right) i_{\mathrm{sd}}^{*}
\end{aligned}
$$

Therefore, we can determine the following differential equation:

$$
\begin{aligned}
\phi_{\mathrm{rd}} \dot{\phi}_{\mathrm{rd}}+\phi_{\mathrm{rq}} \dot{\phi}_{\mathrm{rq}}= & \frac{1}{\tau_{\mathrm{r}}} \phi_{\mathrm{rd}}^{2}+(\omega-p \boldsymbol{\Omega}) \phi_{\mathrm{rd}} \phi_{\mathrm{rq}}+\frac{M}{\tau_{\mathrm{r}}} \phi_{\mathrm{rd}} i_{\mathrm{sd}}^{*} \\
& -\frac{1}{\tau_{\mathrm{r}}} \phi_{\mathrm{rq}}^{2}-\left(\omega_{\mathrm{s}}-p \boldsymbol{\Omega}\right) \phi_{\mathrm{rd}} \phi_{\mathrm{rq}}
\end{aligned}
$$

For simplicity of calculation, we note $\left\|\phi_{\mathrm{r}}\right\|^{2}=\phi_{\mathrm{r}}^{2}$.

The differential output equation of system (17) is expressed by the following equation:

$\dot{\phi}_{\mathrm{r}}^{2}=2 \phi_{\mathrm{rd}} \dot{\phi}_{\mathrm{rd}}+2 \phi_{\mathrm{rq}} \dot{\phi}_{\mathrm{rq}}$

Equation (18) becomes:

$\dot{\phi}_{\mathrm{r}}^{2}=\frac{2}{\tau_{\mathrm{r}}} \phi_{\mathrm{r}}^{2}+\frac{2 M}{\tau_{\mathrm{r}}} \phi_{\mathrm{rd}} i_{\mathrm{sd}}^{*}$

As the open loop dynamic of the rotor flux is directly related to the rotor time constant, the multiplication of this dynamic by a factor of two is generally acceptable for the regulation of $\phi_{\mathrm{r}}^{* 2}$ to obtain a linear closed loop transfer type (22):

$\dot{\phi}_{\mathrm{r}}^{2}=-\frac{2}{\tau_{\mathrm{r}}} \phi_{r}^{2}+\frac{2}{\tau_{\mathrm{r}}} \phi_{\mathrm{r}}^{2 *}$

Let's consider the following linear control law illustrated in Fig. 1.

Where:

$n_{\mathrm{sl}}=\omega_{\mathrm{s}}-p \Omega$

and

$i_{\mathrm{sd}}^{*}=\frac{1}{M} \frac{\phi_{\mathrm{r}}^{2 *}}{\phi_{\mathrm{rd}}}$ with $\phi_{\mathrm{r}}^{2}=\frac{1}{1+\tau_{\mathrm{r}} / 2 p} \phi_{\mathrm{r}}^{* 2}$ 
This control law (23) does not involve the mechanical speed $\Omega$. Through the simplification of coupling terms (18), the perturbation of $\phi_{\mathrm{r}}$ by the term $\left(\omega_{\mathrm{s}}-p \boldsymbol{\Omega}\right)$ no longer exists. The regulation of $\phi_{\mathrm{r}}^{2}$ by the approach (23) is then totally independent of the operating point in the torque-speed plant.

\section{LPV torque controller design}

Consider the torque equation in $(d, q)$ frame given by the following relation:

$C_{\mathrm{m}}=\frac{M}{L_{\mathrm{r}}}\left(\phi_{\mathrm{rd}}^{*} i_{\mathrm{sq}}^{*}-\phi_{\mathrm{rq}}^{*} i_{\mathrm{sd}}^{*}\right)$

The equality $i_{\mathrm{sq}}=i_{\mathrm{sq}}^{*}=0$ is satisfied at any moment and leads to the torque equation below:

$C_{\mathrm{m}}=-\frac{M}{L_{\mathrm{r}}} \phi_{\mathrm{rq}} i_{\mathrm{sd}}$

The substitution of (23) in (25) gives:

$C_{\mathrm{m}}=-\frac{1}{L_{\mathrm{r}}}\left(\frac{\phi_{\mathrm{rq}}}{\phi_{\mathrm{rd}}}\right) \phi_{r}^{2 *}$

By supposing that the $\phi_{\mathrm{r}}^{2 *}$ is constant, the torque dynamic can be obtained by the differential of Eq. (26):

$\dot{C}_{\mathrm{m}}=\frac{1}{L_{\mathrm{r}}}\left[\frac{\phi_{\mathrm{r}}^{2 *}}{\phi_{\mathrm{rd}}^{2}}\right]\left(\phi_{\mathrm{rq}} \dot{\phi}_{\mathrm{rd}}-\phi_{\mathrm{rd}} \dot{\phi}_{\mathrm{rq}}\right)$

By substituting the expression of $\dot{\phi}_{\text {rd }}$ and $\dot{\phi}_{\text {rq }}$ into Eq. (27), one can write:

$\dot{C}_{\mathrm{m}}=\frac{1}{L_{\mathrm{r}}}\left[\frac{\phi_{\mathrm{r}}^{2 *}}{\phi_{\mathrm{rd}}^{2}}\right]\left(\left(\omega_{\mathrm{s}}-p \boldsymbol{\Omega}\right)\left(\phi_{\mathrm{rd}}^{2}+\phi_{\mathrm{rq}}^{2}\right)+\frac{M}{\tau_{\mathrm{r}}} \phi_{\mathrm{rq}} i_{\mathrm{sd}}\right)$

From (27) and (27), the torque dynamic is given by:

$\dot{C}_{\mathrm{m}}=-\frac{1}{\tau_{\mathrm{r}}}\left[\frac{\phi_{r}^{2 *}}{\phi_{\mathrm{rd}}^{2}}\right] C_{\mathrm{m}}+\frac{\phi_{\mathrm{r}}^{2 *}}{L_{\mathrm{r}}}\left[\frac{\phi_{\mathrm{r}}^{2 *}}{\phi_{\mathrm{rd}}^{2}}\right]\left(\omega_{\mathrm{s}}-p \boldsymbol{\Omega}\right)$

The system can still be put in the general LPV form:

$\dot{C}_{\mathrm{m}}=A_{\mathrm{c}}(\theta) C_{\mathrm{m}}+B_{\mathrm{c}}(\theta)\left(\omega_{\mathrm{s}}-p \boldsymbol{\Omega}\right)$

With:

$$
\left\{\begin{array}{l}
l A(\theta(t))=-\frac{1}{\tau_{r}} \theta(t), \\
B(\theta(t))=\frac{\phi_{r}^{2 *}}{L_{r}}\left(\omega_{s}-p \boldsymbol{\Omega}\right) \theta(t)
\end{array} \quad \text { Avec } \theta(t)=\left[\frac{\phi_{r}^{2 *}}{\phi_{\mathrm{rd}}^{2}(t)}\right]\right.
$$

\subsection{LPV controller synthesis}

Consider an open loop LPV system $P$ described by the following set of equations:

$$
P:\left\{\begin{array}{l}
\dot{x}(t)=A(\theta(t)) x(t)+B_{1}(\theta(t)) w(t)+B_{2}(\theta(t)) u(t), \\
z(t)=C_{1}(\theta(t)) x(t)+D_{11}(\theta(t)) w(t)+D_{12}(\theta(t)) u(t), \\
y(t)=C_{2}(\theta(t)) x(t)+D_{21}(\theta(t)) w(t),
\end{array}\right.
$$

where $y$ denotes the measured output, $z$ is the controlled output, $w$ is the reference and the disturbance inputs and $u$ is the control inputs. The matrices in (9) are affine functions of the parameter vector that varies in polytope $\Theta$ with vertices $\theta_{1}, \ldots, \theta_{j}$ that is:

$\theta(t) \in \Theta=\operatorname{conv}\left\{\theta_{1}, \ldots, \theta_{j}\right\} \triangleq\left\{\sum_{j=1}^{r} \alpha_{i} \theta_{j}, \alpha_{j} \geq 0, \sum_{j=1}^{r} \alpha_{j}=1\right\}$

The LPV synthesis problem consists in finding a controller $K(\theta)$ described by:

$K(\theta):\left\{\begin{array}{l}\dot{x}_{K}(t)=A_{K}(\theta(t)) x_{K}(t)+B_{K}(\theta(t)) y(t) \\ u(t)=C_{K}(\theta(t)) x_{K}\end{array}\right.$

Such that closed-loop system (31) (with input $w$ and output $z$ ) is internally stable and the induced $L_{2}$ norm of $w \rightarrow z$ is bounded by a given number $\gamma \succ 0$ for all possible parameter trajectories.

$P_{\mathrm{cl}}:\left[\begin{array}{l}\dot{\xi}(t) \\ z(t)\end{array}\right]=\left[\begin{array}{ll}A_{\mathrm{cl}}(\theta(t)) & B_{\mathrm{cl}}(\theta(t)) \\ C_{\mathrm{cl}}(\theta(t)) & D_{\mathrm{cl}}(\theta(t))\end{array}\right]\left[\begin{array}{c}\xi(t) \\ w(t)\end{array}\right]$

The characterization of robust stability and performance for closed-loop system $P_{c l}(31)$ is proved by the following theorem:LPV system (31) would have a quadratic stability and gain level if there exists a matrix such that:

$$
\left[\begin{array}{ccc}
A_{\mathrm{cl}}^{T}(\theta) X+X A_{\mathrm{cl}}(\theta) & X B_{\mathrm{cl}}(\theta) & C_{\mathrm{cl}}(\theta)^{T} \\
B_{\mathrm{cl}}(\theta)^{T} X & -\gamma I & D_{\mathrm{cl}}(\theta)^{T} \\
C_{\mathrm{cl}}(\theta) & D_{\mathrm{cl}}(\theta) & -\gamma I
\end{array}\right] \prec 0
$$

This implies for synthesis inequalities (35) that, without loss of generality, we can replace the search over the polytope $\Theta$ by the search over the vertices of this set consequently, condition (34) can be reduced to a finite set of linear matrix inequalities (LMI).

\subsection{Computation of self-gain scheduled LPV controller}

We assume that parameter dependence of the plant $\mathrm{P}$ is affine and $\Theta$ is polytope with vertices $\theta_{j}, j=1,2, \ldots, r$. Accord- 
Fig. 2 Diagram of flux variation
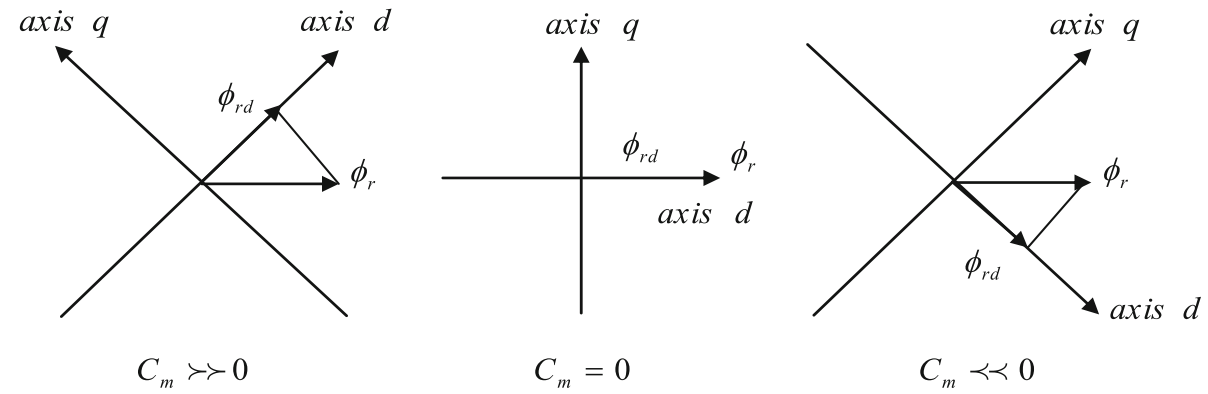

ing to the result in [14], one LPV controller $K(\theta)$ can be computed through the following steps:

- Computing the vertex controllers as follows:

$$
K_{j=}\left(A_{K_{j}}, B_{K_{j}}, C_{K_{j}}, 0\right),(1 \leq j \leq r)
$$

- Solving the set of LMIs (13) and (14):

$$
\begin{aligned}
& {\left[\begin{array}{cccc}
X A_{j}+\hat{B}_{K_{j}} C_{2_{j}}+* & * & * & * \\
\hat{A}_{K_{j}}^{T}+A_{j} & A_{j} Y+B_{2_{j}} \hat{C}_{K_{j}}+* & * & * \\
\left(X B_{1_{j}}+\hat{B}_{K_{j}} D_{21_{j}}\right)^{T} & B_{1 j}^{T} & -\gamma I & * \\
C_{1_{j}} & C_{1 j} Y+D_{12_{j}} \hat{C}_{K_{j}} & D_{11_{j}}-\gamma I
\end{array}\right]} \\
& <0 \text { and }\left[\begin{array}{cc}
X & I \\
I & Y
\end{array}\right]<0
\end{aligned}
$$

Where $(*, *)$ denotes terms whose expressions follow the requirement that the matrix is self-adjoint. This step gives $\left(\hat{A}_{K_{j}}, \hat{B}_{K_{j}}, \hat{C}_{K_{j}}\right)$ and symmetric matrices $X$ and $Y$.

- Computing $A_{K_{j}}, B_{K_{j}}$ and $C_{K_{j}}$ by:

$$
\begin{aligned}
& A_{K j}=N^{-1}\left(\hat{A}_{K j}-X A_{j} Y-\hat{B}_{K j} C_{2 j} Y\right. \\
& \left.\quad-X B_{2 j} \hat{C}_{K j}\right) M^{-T} \text { and } B_{K j}=N^{-1} \hat{B}_{K j}
\end{aligned}
$$

- $C_{K j}=\hat{C}_{K j} M^{-T}$, where $N$ and $M$ are matrices such that $I-X Y=N M^{T}$.

Finally, the state-space matrices of the LPV polytopic controller $K(\theta)$ as a convex combination of the vertex controllers are given by.

$$
\left[\begin{array}{cc}
A_{K} & B_{K} \\
C_{K} & 0
\end{array}\right](\theta)=\sum_{j=1}^{r} \alpha_{j}\left[\begin{array}{cc}
A_{K_{j}} & B_{K_{j}} \\
C_{K_{j}} & 0
\end{array}\right]
$$

\subsection{Synthesis of the LPV torque controller and rotor flux observer}

Before the synthesis of the torque controller, we should beforehand to characterize, the variations of the $\phi_{\mathrm{rd}}$ component as a function of $\left|C_{\mathrm{m}}\right|$. Figure 2 illustrates the evolution for three remarkable values of $C_{\mathrm{m}}$ by taking the vector $\phi_{\mathrm{r}}$ as a phase reference:

Figure 2 Evolution of the component $\phi_{\mathrm{rd}}$ according to $\left|C_{\mathrm{m}}\right|$ for 3 remarkable values with $\phi_{\mathrm{r}}$ vector as a phase reference. In this figure, the stator current vector $i_{\text {sd }}$ is not visible since it coincides with the $d$ axis.

\subsection{Polytopic torque controller design}

In this section, attention is focused on the design of the torque feedback controller. Let us consider state Eq. (30). It constitutes an affine parameter-dependent plant if the rotor flux $\left[\frac{\phi_{\mathrm{r}}^{* 2}}{\phi_{\mathrm{rd}}}\right]$ is taken as the varying parameter, and $\phi_{\mathrm{rd}} \in$ $\left[\begin{array}{ll}0.8 & 1.11\end{array}\right]$.

More precisely, let us define the subsystem $G$ with state vector $x=C_{\mathrm{m}}$ having $y=C_{\mathrm{m}}$ as output and $u=\left(\omega_{\mathrm{s}}-p \boldsymbol{\Omega}\right)$ as input. The system can be written as follows:

$G:\left\{\begin{array}{c}\dot{C}_{\mathrm{m}}=\left(A_{0}+\left[\frac{\phi_{\mathrm{r}}^{2 *}}{\phi_{\mathrm{rd}}^{2}}\right] A_{1}\right) C_{\mathrm{m}}+B\left[\frac{\phi_{\mathrm{r}}^{2 *}}{\phi_{\mathrm{rd}}^{2}}\right] u \\ C_{\mathrm{m}}=C C_{\mathrm{m}}\end{array}\right.$

Alternatively, G admits the following LPV polytopic statespace representation:

$G: \alpha(t) S_{1}+(1-\alpha(t)) S_{0}$

With:

$\tilde{A}_{1}=A_{0}+\left[\frac{\phi_{r}^{2 *}}{\phi_{\mathrm{rdmax}}^{2}}\right] A_{1}, 0 \leq \alpha(t)=\frac{\left[\frac{\phi_{r}^{2 *}}{\phi_{\mathrm{rd}}^{2}}\right]-\left[\frac{\phi_{r}^{2 *}}{\phi_{\mathrm{rdmin}}^{2}}\right]}{\left[\frac{\phi_{r}^{2 *}}{\phi_{\mathrm{rdmax}}^{2}}\right]-\left[\frac{\phi_{r}^{2 *}}{\phi_{\mathrm{rdmin}}^{2}}\right]} \leq 1$

The reader may refer to [17] for a general theory and control of LPV systems.

The polytopic controller $K(\theta(t))$ as it is shown in Fig. 3 is a torque LPV feedback controller allowing to track the set point reference where $w=$. The input of controller $e$ is the difference between $C_{\mathrm{m}}^{*}$ and $C_{\mathrm{m}}$ obtained from $G$ and $U=\omega_{\mathrm{s}}-p \Omega$. 


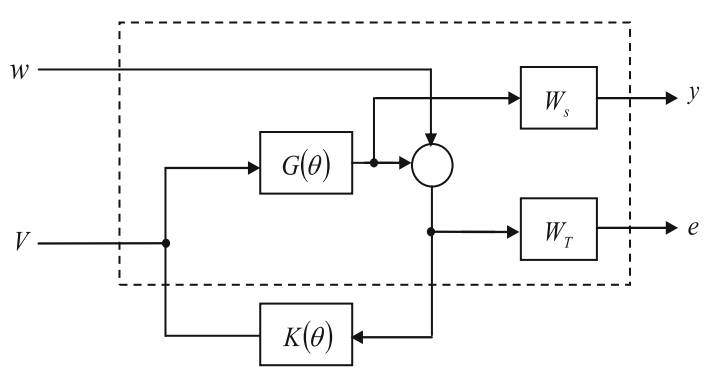

Fig. 3 Structure of LPV controller with mixed sensitivity method

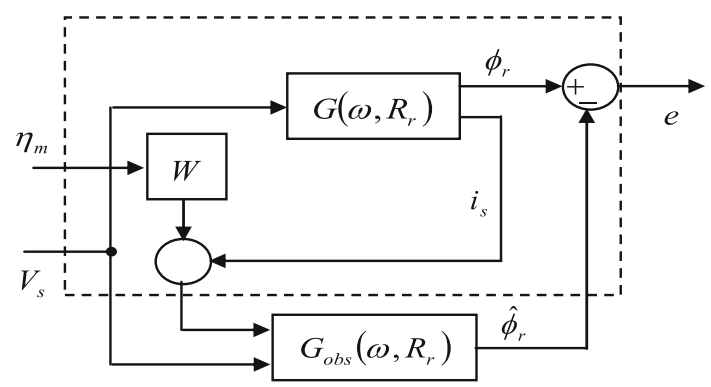

Fig. 4 Sensitivity structure for LPV flux observer

$K(\theta)$ has to provide satisfactory performance over the whole motor operating range. The $L_{2}-$ gain bound $y$ guaranteeing the closed-loop system performance and stability is equal in this case to $(\gamma=0.039283)$. The used weighting functions are defined by:

$W_{s}=0.0015$ and $W_{T}=\frac{5}{s+0.02}$

\subsection{Design of rotor flux and torque observer}

The LPV rotor flux observer and torque estimator are a crucial part of the control system design, since they provide the necessary information upon which the controllers action is based.

The rotor flux observer, as it is shown in Fig. 4, has been performed using the induction motor model [17] and standard problem structure where the controller is in fact the observer and the same optimization mechanism is used to achieve the synthesis. The robustness is improved by taking into account rotor resistance and mechanical speed variations where $\boldsymbol{\theta}(t)=(\boldsymbol{\Omega}, R r)$. The design consists of finding $u=G_{o b s} \cdot y$ to minimize, closed loop $H_{\infty}$ LPV norm from $w$ to $z$.

Where $w=\left[V_{s \alpha}, V_{s \beta}, \eta_{m}\right]$ constitutes the exogenous inputs, $z=\left[e_{\alpha}, e_{\beta}\right]$ represent the outputs $y=\left[i_{s \alpha}, i_{s \beta}\right]$ are the measurements and $u^{T}=\left[\hat{\phi}_{s \alpha}, \hat{\phi}_{s \beta}\right]$ is the control input.

The tracking errors of rotor flux components are given by $e_{\alpha}=\phi_{r \alpha}-\hat{\phi}_{r \alpha}$ and $e_{\beta}=\phi_{r \beta}-\hat{\phi}_{r \beta}$. The robust quadratic stability and performance is achieved for $\gamma=0.0086$ using the following shaping filter:

$W=\operatorname{diag}\left(\frac{0.006}{s+7.3 \times 10^{3}}, \frac{0.006}{s+7.3 \times 10^{3}}\right)$

\subsection{Stator current-based MRAS torque observer}

The MRAS technique based on the stator current uses the latter as a state variable for speed and torque estimation. It provides a reference to the torque controller. This technique proposed by [22] allows a good performance not only for speed and torque estimation but also for sensorless control [21,22].The measured and estimated stator currents are given by the following equations:

$i_{s \alpha}=\frac{1}{M}\left(\phi_{r \alpha}+\omega_{r} \tau_{r} \phi_{r \beta}+\tau_{r} \dot{\phi}_{r \alpha}\right)$

$i_{s \beta}=\frac{1}{M}\left(\phi_{r \beta}+\omega_{r} \tau_{r} \phi_{r \alpha}+\tau_{r} \dot{\phi}_{r \beta}\right)$

$\hat{i}_{s \alpha}=\frac{1}{M}\left(\phi_{r \alpha}+\hat{\omega}_{r} \tau_{r} \phi_{r \beta}+\tau_{r} \dot{\phi}_{r \alpha}\right)$

$\hat{i}_{s \beta}=\frac{1}{M}\left(\phi_{r \beta}+\hat{\omega}_{r} \tau_{r} \phi_{r \alpha}+\tau_{r} \dot{\phi}_{r \beta}\right)$

The difference between the measured and estimated currents is given by:

$i_{s \alpha}-\hat{i}_{s \alpha}=\frac{\tau_{r}}{M}\left(\phi_{r \beta}\left(\omega_{r}-\hat{\omega}_{r}\right)\right)$

$i_{s \beta}-\hat{i}_{s \beta}=\frac{\tau_{r}}{M}\left(\phi_{r \alpha}\left(\omega_{r}-\hat{\omega}_{r}\right)\right)$

In order to determine the speed error, the currents differences are multiplied by the two-flux components:

$\left(i_{s \alpha}-\hat{i}_{s \alpha}\right) \phi_{r \beta}+\left(i_{s \beta}-\hat{i}_{s \beta}\right) \phi_{r \alpha}=\frac{M}{\tau_{r}}\left(\phi_{r \alpha}^{2}+\phi_{r \beta}^{2}\right)\left(\omega_{r}-\hat{\omega}_{r}\right)$

This operation leads to the following expression:

$\left(\omega_{r}-\hat{\omega}_{r}\right)=\left[\left(i_{s \alpha}-\hat{i}_{s \alpha}\right) \phi_{r \beta}+\left(i_{s \beta}-\hat{i}_{s \beta}\right) \phi_{r \alpha}\right] \cdot \frac{\tau_{r}}{M} \frac{1}{\left(\phi_{r \alpha}^{2}+\phi_{r \beta}^{2}\right)}$

The estimated torque is directly found by multiplying the estimated stator current by the rotor flux.

$\hat{C}_{\mathrm{m}}=-p \cdot \frac{M}{L_{\mathrm{r}}} \cdot \hat{i}_{\mathrm{sd}} \cdot \phi_{\mathrm{rq}}$

The stability of this algorithm is studied by the hyper-stability Popov criterion. For more details the reader can consult [22]. 
Fig. 5 General block diagram of the suggested IM control scheme

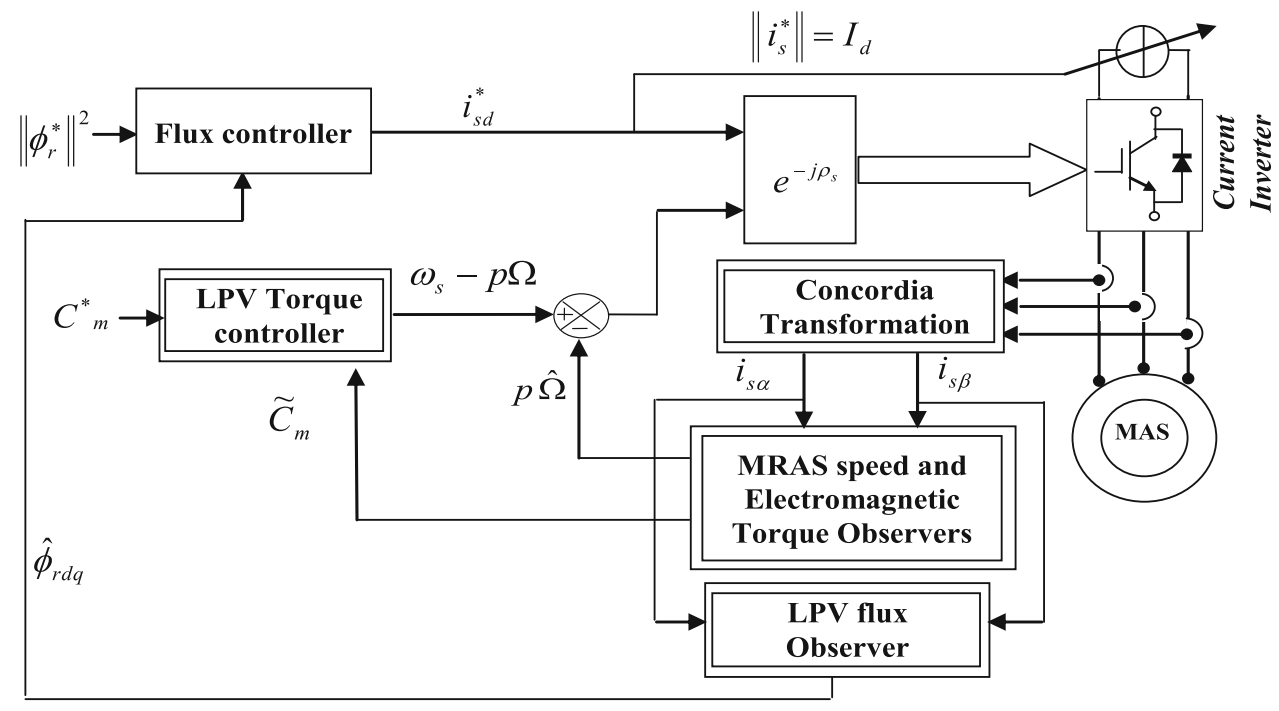

\section{Stability analysis}

In order to check the stability of the control structure, we shall use a Lyapunov function that depends on the variant parameter as follows:

$V(x, p)=x^{T} Q(\theta)^{-1} x$ with: $Q(\theta)=Q_{0}+\theta_{1} Q_{1}+\cdots+\theta_{n} Q_{n}$

For such Lyapunov function, the stability condition $\frac{\mathrm{d} V(x, p)}{\mathrm{d} t}<0$ is equivalent to:

$Q(\theta) A^{T}(\theta)+A(\theta) Q(\theta)-\frac{\mathrm{d} Q}{\mathrm{~d} t}<0$

- $\boldsymbol{\theta}(t)=\left[\frac{\phi_{\mathrm{r}}^{2 *}}{\phi_{\mathrm{rd}}^{2}}\right] \in V \times T$ for the torque controller:

$$
Q(\theta) A(\theta)^{T}+A(\theta) Q(\theta)^{T}-Q(\tau)-Q_{0}
$$

- For $\theta \in V$ and $i=1, \ldots, n$ :

$$
\begin{array}{r}
A_{i} Q_{i}+Q_{i} A_{i}+A_{i}^{T} Q(\theta)+Q(\theta) A_{i}+ \\
A(\theta)^{T} Q_{i}+Q_{i} A(\theta)-Q(\tau)-Q_{0}+M_{i} \geq 0
\end{array}
$$

- $Q(\theta)>I$ for all $M_{i} S 0 \theta \in V$.

The MATLAB function pdlstab makes it possible to check the feasibility conditions when $t_{\min }<0$.

The system composed of LPV torque controller and LPV flux observer is stable since the observer is quadratically stable and then the system is stable in specified range for $t_{\min }=-0.0035$.

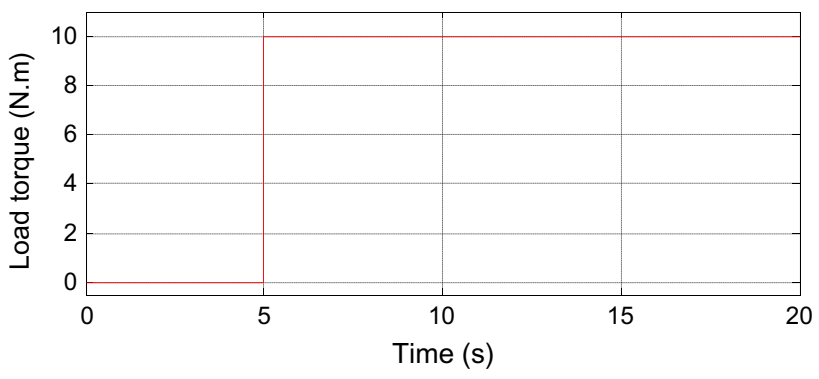

Fig. 6 Evolution of the load torque variation

\section{Simulation and experimental results}

\subsection{Simulation results of the new control structure}

Figure 5 gives the general control structure of the induction motor where the mechanical speed and the electromagnetic torque are given by the MRAS observer providing reference to the torque controller. The flux given by the LPV flux observer is controlled by a linear controller (23).

The simulation objective is to test the dynamic performance of the torque loop. The dynamic behavior of the magnitudes $\phi_{\mathrm{r}}, C_{\mathrm{m}}$ and $i_{\mathrm{sd}}$ is tested under the following simulation conditions: a load torque of $10 \mathrm{Nm}$ is applied at $5 \mathrm{~s}$ in Fig. 6. The rotor speed response follows the specified reference as shown in Figs. 7, 8 and 9. At $12.5 \mathrm{~s}$ a reversible speed test is carried out from $100 \mathrm{rd} / \mathrm{s}$ to $-100 \mathrm{rd} / \mathrm{s}$ at rated motor load. Figures 10, 11, 12 and 13 confirm the good dynamic behavior of the cited quantities. One can note that torque is not affected by the flux variation and the adaptation of the parameters can be very rapid in response to sudden variations of the operating point, which confirms the choice of the LPV regulator. 


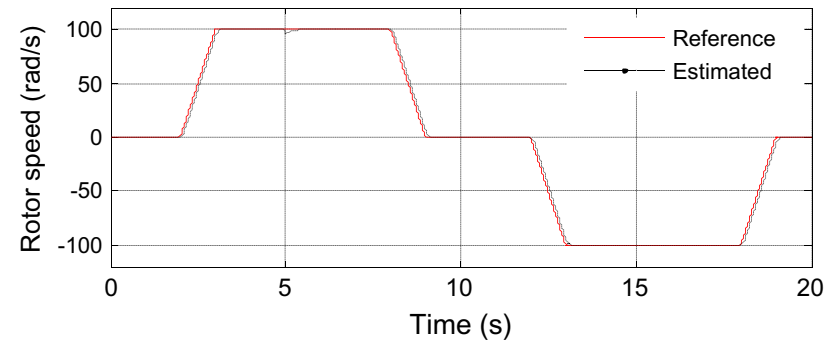

Fig. 7 Evolution of the reference and the estimated speeds of induction motor

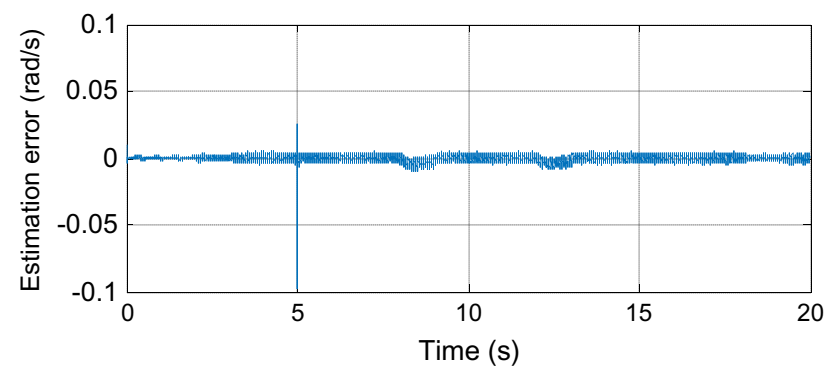

Fig. 8 Speed estimation error

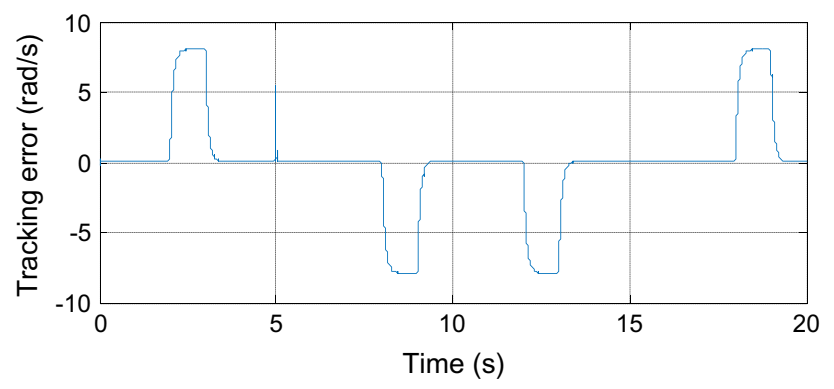

Fig. 9 Speed tracking error

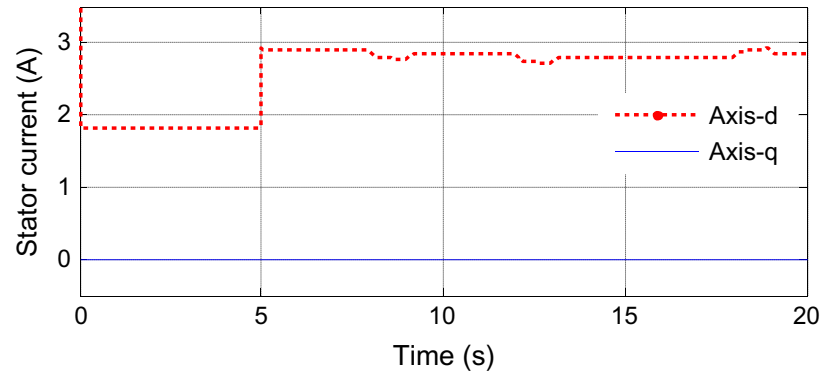

Fig. $10 \mathrm{I}_{\mathrm{sd}}$ and $\mathrm{I}_{\mathrm{sq}}$ stator currents

To test the impact of rotor time constant variation at low speed, the proposed control structure is simulated where a load torque variation of $10 \mathrm{Nm}$ is applied at $t=5 \mathrm{~s}$ and at $t=$ $7 \mathrm{~s}$ a rotor time constant variation is introduced as illustrated in Fig. 14. It is clear that the speed is close to its reference and the tracking error is small and converges quickly to zero without influence of the load torque and rotor time constant variation as shown in Figs. 15 and 16. Moreover, one can

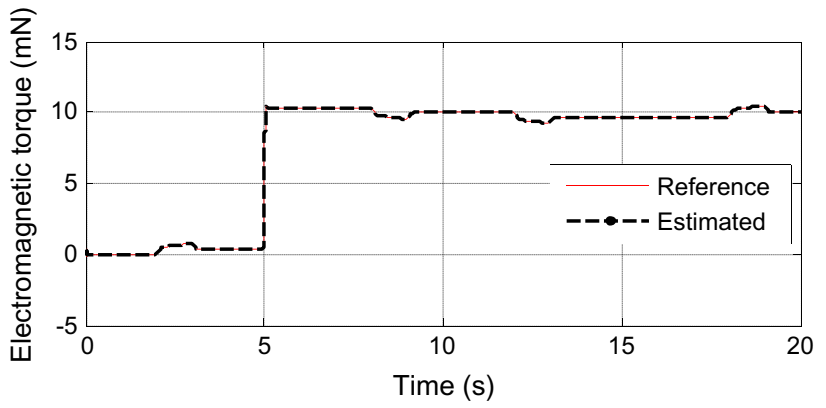

Fig. 11 Electromagnetic torque evolution

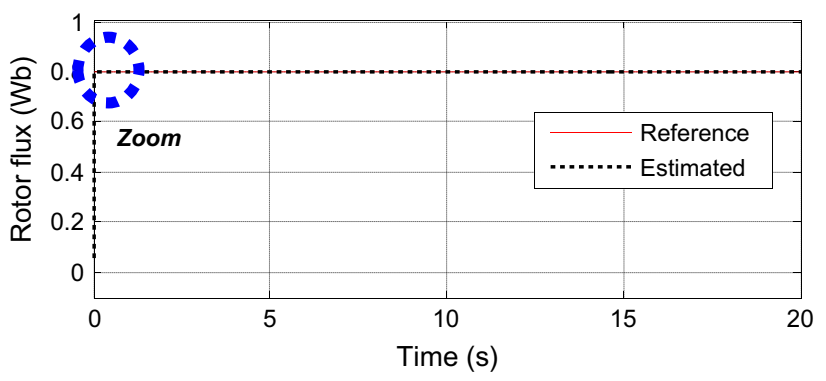

Fig. 12 Rotor flux

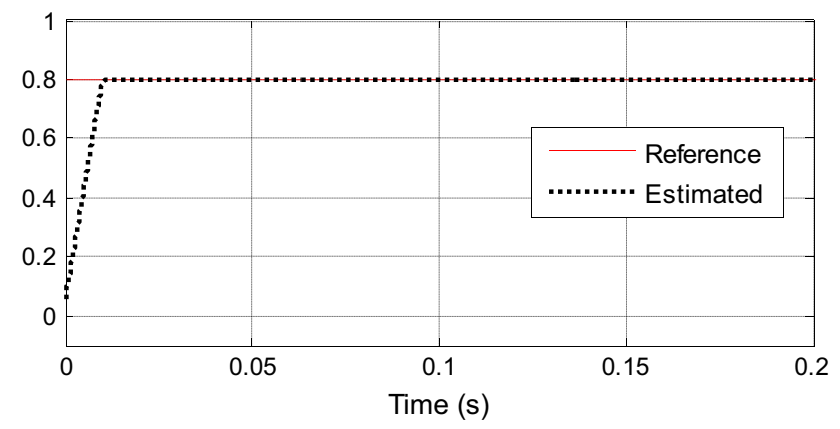

Fig. 13 Zoom of Rotor flux

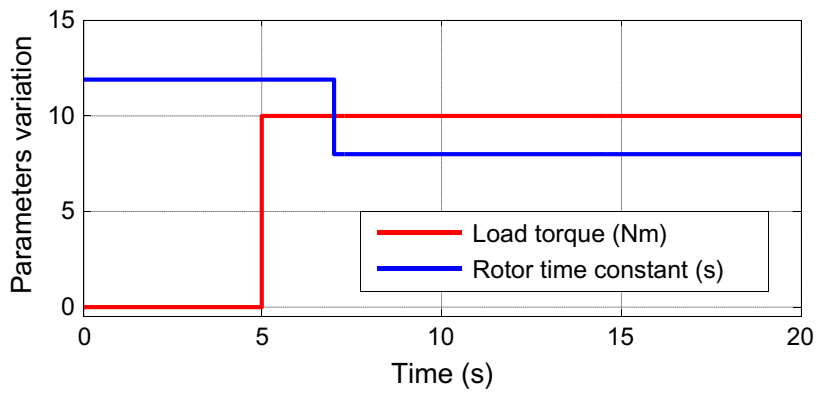

Fig. 14 Load torque and rotor time constant variations

observe a perfect superposition of electromagnetic torque and its reference as depicted in Fig. 17. All these arguments prove the efficiency of the proposed control structure. 


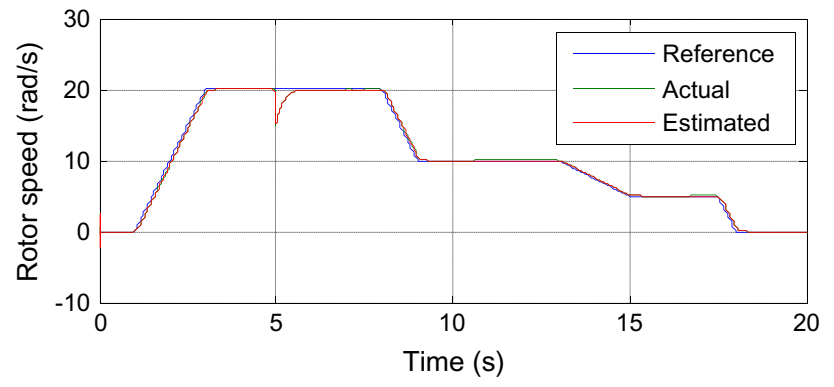

Fig. 15 Evolution of reference, actual and estimated speeds of induction motor

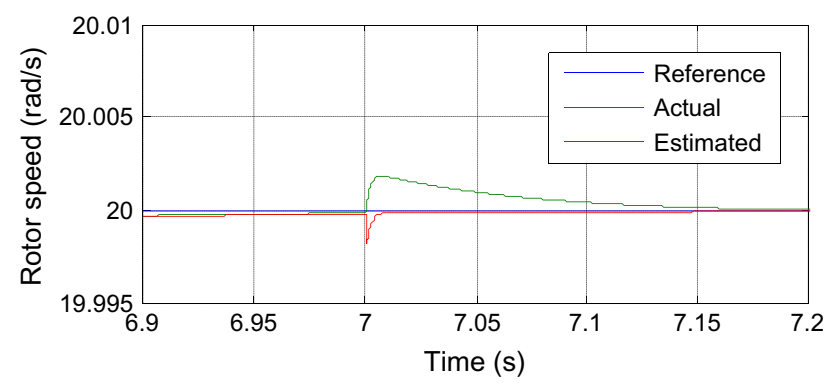

Fig. 16 Zoom of reference, actual and estimated speeds

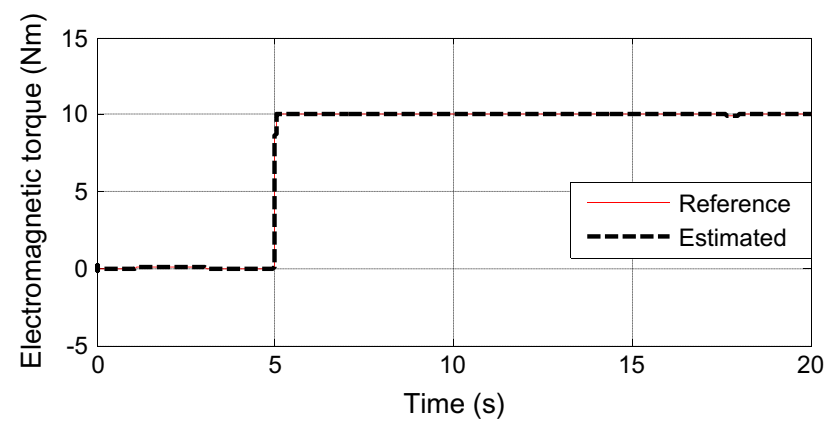

Fig. 17 Electromagnetic torque

\subsection{Comparative study of new approach with IFOC and DTC control strategies}

In order to confirm the performances of the new control structure, a comparison between the results obtained by DTC with 12 sectors, IFOC and the new approach was fulfilled under MATLAB/Simulink. In the three cases, the speed is controlled in a closed loop by a simple PI, using the same simulation conditions. A load torque is applied to the motor at $\mathrm{t}=5 \mathrm{~s}$. It can be clearly observed from Figs. 18 and 19 that the new structure can provide a quick response, a better rejection of disturbance (load torque) compared to the DTC and the IFOC. It confirms the insensitivity to rotor resistance of the speed response compared to the IFOC control. Figures 20 and 21 show clearly that the torque response under the proposed control system is similar to the one obtained under DTC; but faster than that achieved under IFOC. Fur-

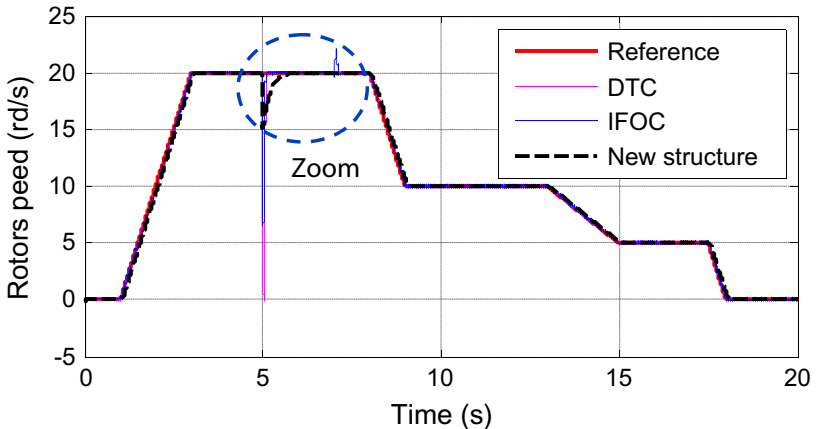

Fig. 18 Rotor speed response: new approach, IFOC, DTC

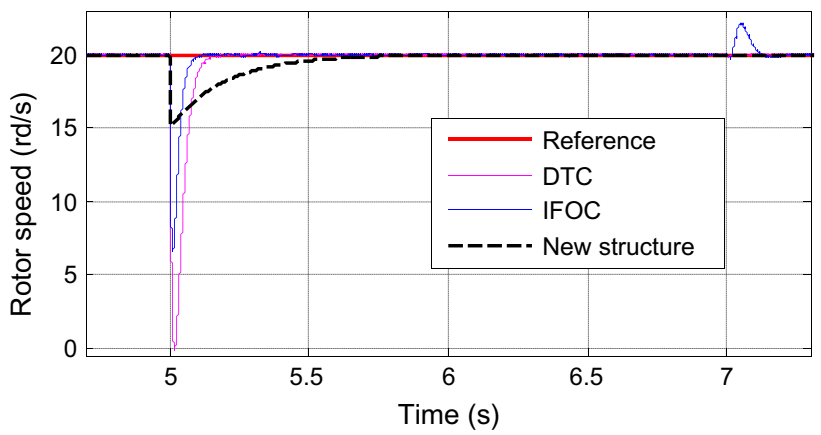

Fig. 19 Zoom of the rotor speed response: new approach, IFOC, DTC

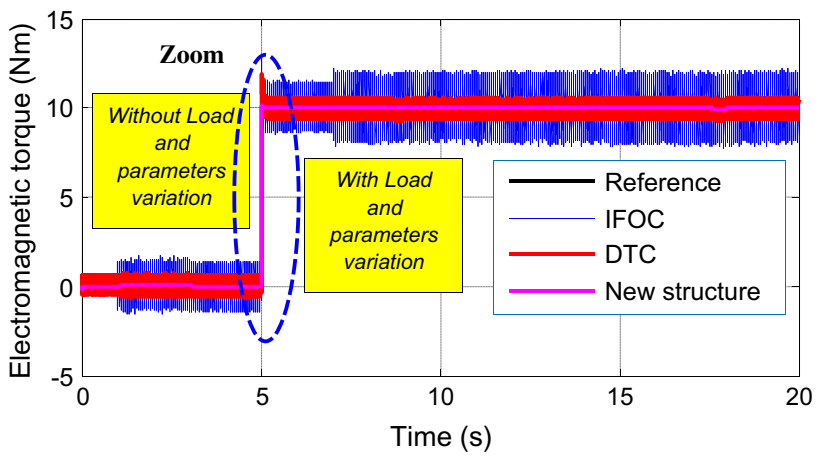

Fig. 20 Electromagnetic torque response: new approach, IFOC, DTC

thermore, it shows that the torque ripples under the proposed control are less than those obtained by DTC. In summary, it is evident that new approach can provide a better robustness with respect to resistance variation then that achieved by IFOC.

\subsection{Comparative study of new approach with Sliding mode order 1 control strategy}

In order to evaluate further the control system, a closed-loop speed and torque control with simple PI (proportional integral) and sliding mode controller, respectively, for speed and torque are applied to the motor drive with all two control methods (LPV and SM) to be able to examine the transient 


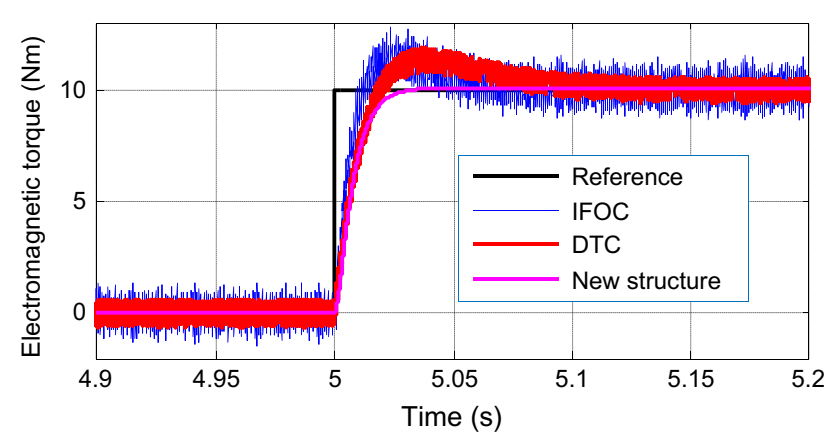

Fig. 21 Zoom of the electromagnetic torque response: new approach, IFOC, DTC

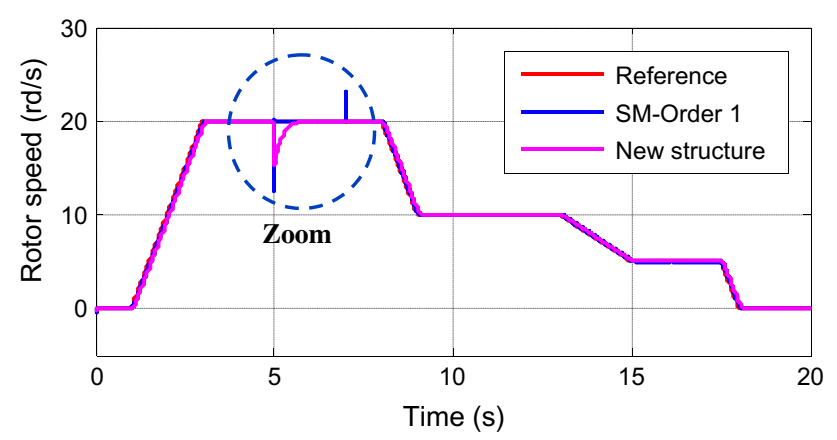

Fig. 22 Rotor speed response: new approach, SM-Order 1

state and the steady state performances of the motor. The same loading is used for all the control systems. After the motor speeds up to the commanded speed, a nominal load is applied to the motor at $t=5 \mathrm{~s}$. Figures 22 and 23 show the motor speed under the two control systems. It is seen that the proposed control system is capable of controlling the motor speed as well as sliding mode. Figures 24 and 25 show the motor developed torque under the two control systems. It is seen that the two torque curves are quite similar. Figure 26 confirms that the torque response under the proposed control system is slightly slower than that obtained under sliding mode; it is evident that the torque ripples under the proposed control are less than those under sliding mode. In fact, the proposed method provides a better robustness in comparison with that sliding mode.

As a final result, the achieve simulation results presented above demonstrate that the performance and robustness under the new control structure are to a large extent better than those obtained by DTC, IFOC and SM order 1.

\subsection{Description of the laboratory setup}

Experimental tests are conducted by using dSPACE DS1104 to implement the new control structure. Figure 27 shows the basic structure of the laboratory setup with all parts. The IM stator is fed by a converter controlled directly by the DS1104 board. The encoder is used to measure the mechanical speed.

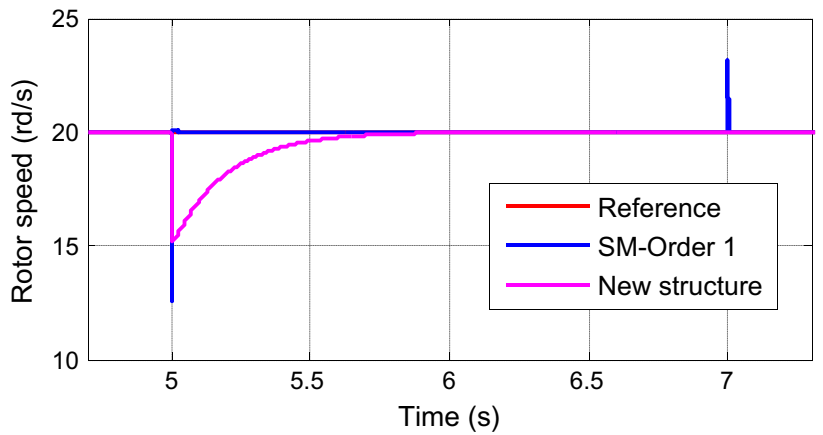

Fig. 23 Zoom of the rotor speed response: new approach, SM-Order 1

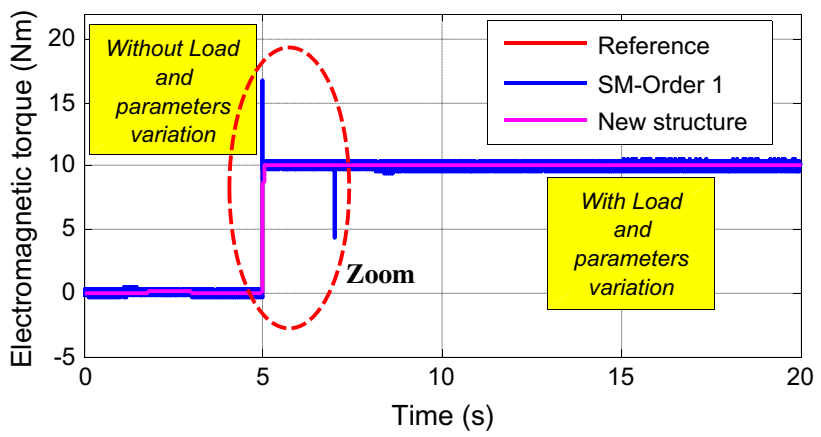

Fig. 24 Electromagnetic torque response: new approach, SM-Order 1

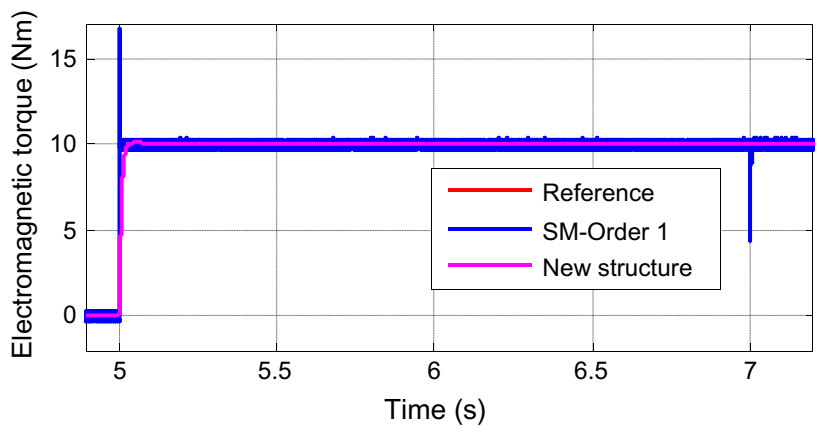

Fig. 25 Zoom of the electromagnetic torque response: new approach, SM-Order 1

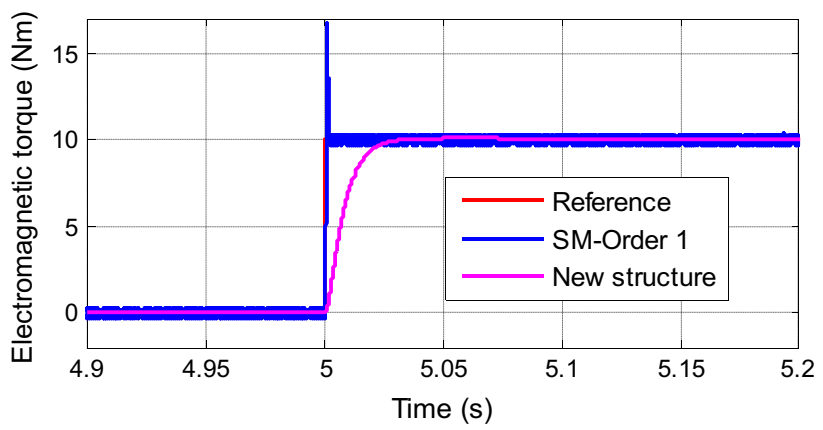

Fig. 26 Zoom of the electromagnetic torque response: new approach, SM-Order 1 
Fig. 27 Structure of the laboratory setup

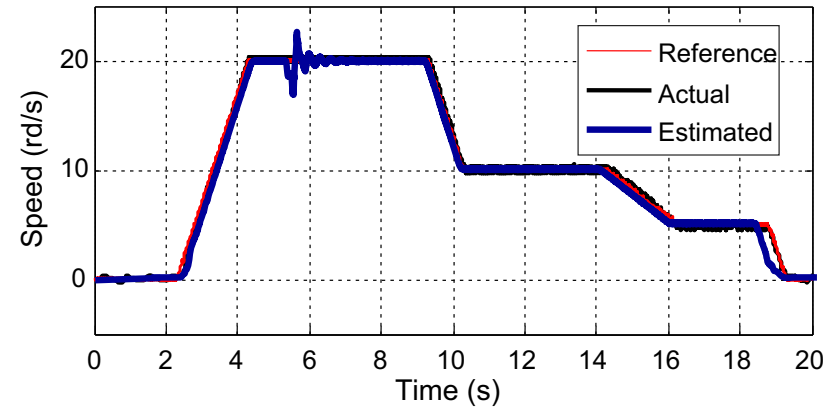

Fig. 28 Rotor speed response

The sensors used for the currents and voltages measure are, respectively, LA-55NP and LV-25P. Furthermore, all parameters of the motor are given in the appendix, and the switching frequency is $11 \mathrm{kHz}$.

\subsection{Experimental results}

Experimental investigation was focused on the torque controller using the proposed approach. Figure 28 shows that the reference, measured (actual), and estimated speed and also the speed reference of the proposed sensorless control. It is observed that the measured and estimated speed is close to each other and converge to the speed reference. Figure 29 shows the estimated and reference torque, we can see that is, the torque has no upper ripple and steady state torque reaches $10 \mathrm{Nm}$ exactly, also the tracking errors are small and converge quickly to zero. Experimental motor currents are shown in Fig. $30 \mathrm{It}$ is observed that is, some current ripples appear at low speed this is due to stator flux variation. However, stator current orientation is well maintained $\left(i_{s q}=0\right)$ It can be seen in Fig. 31 that the rotor flux magnitude is constant, the estimated and the reference rotor flux are close to each other and the trajectory tracking is satisfactory.
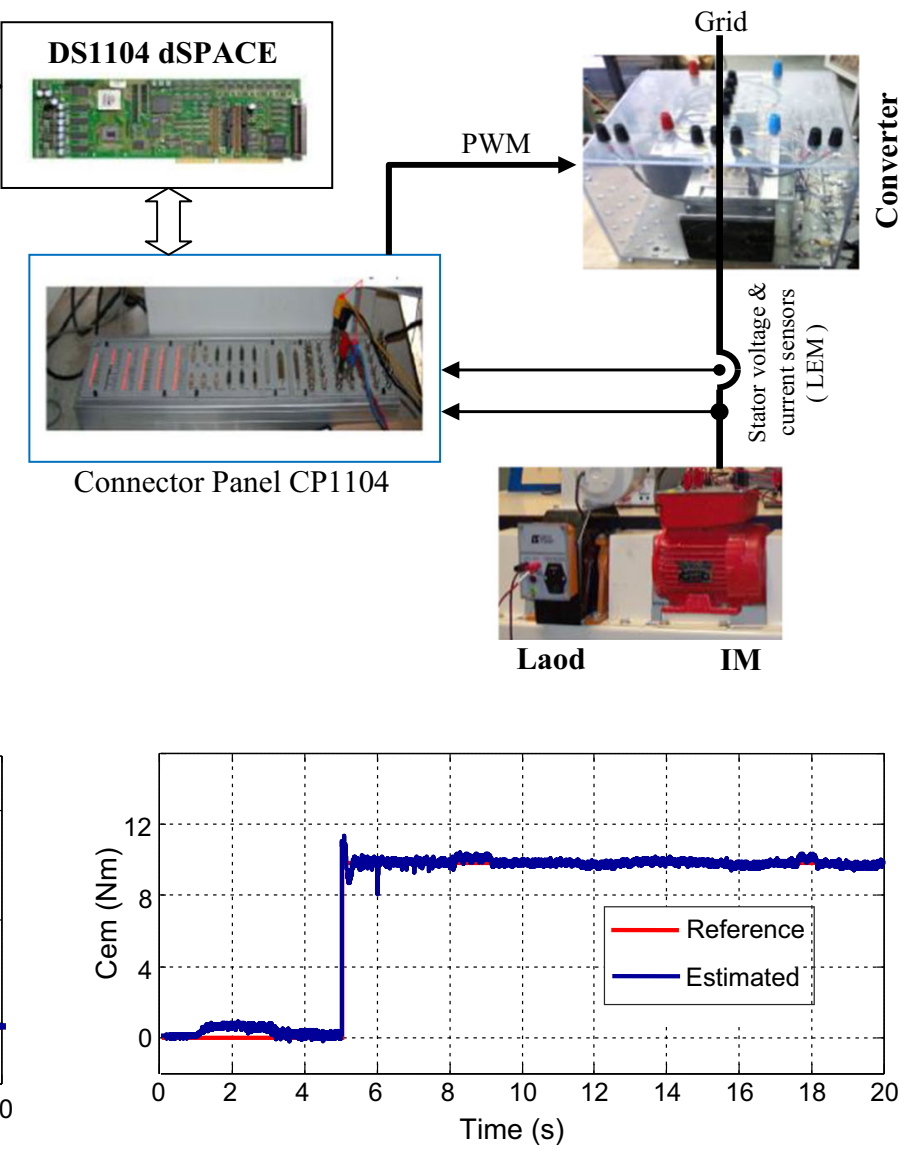

Fig. 29 Electromagnetic torque response

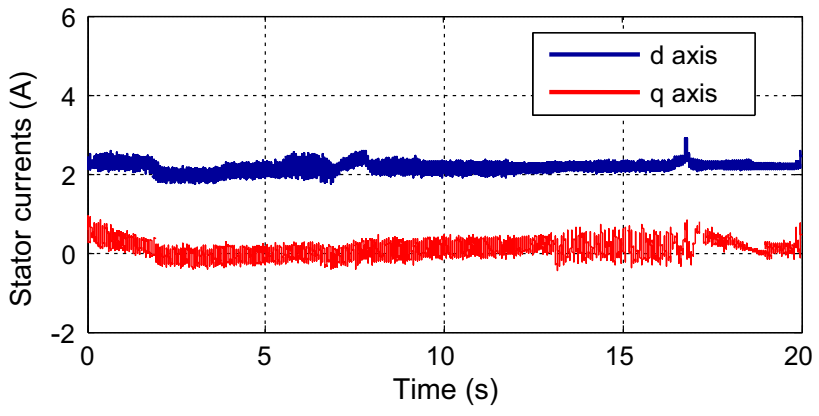

Fig. 30 Stator current

It is observed that both simulation and experimental results are same. The experimental results confirm the effectiveness of our approach.

\section{Conclusion}

Robust LPV torque controller performance under flux variations has been achieved for induction motor. An LMI-based approach with polytopic model in the singularly perturbed system theory frame work has been proposed to design an 


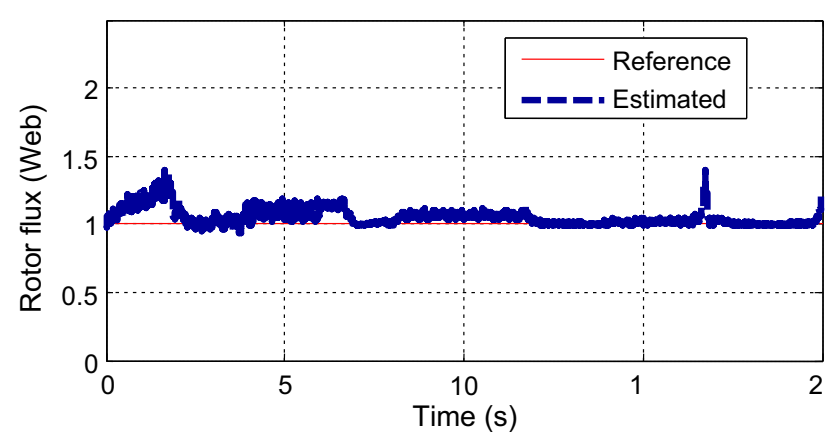

Fig. 31 Rotor flux response

LPV torque controller to track the electromagnetic torque. It is clearly turned out that with the use of the LPV controller the robustness and stability of the whole drive was demonstrated. The main advantage of using singularly perturbed systems is that they provide a systematic way of reducing the induction motor model and in the same way the controller. The simulation and experimental results reveal and demonstrate high performances of the induction motor control according to the profile defined above.

Funding Open Access funding provided by Projekt DEAL.

Open Access This article is licensed under a Creative Commons Attribution 4.0 International License, which permits use, sharing, adaptation, distribution and reproduction in any medium or format, as long as you give appropriate credit to the original author(s) and the source, provide a link to the Creative Commons licence, and indicate if changes were made. The images or other third party material in this article are included in the article's Creative Commons licence, unless indicated otherwise in a credit line to the material. If material is not included in the article's Creative Commons licence and your intended use is not permitted by statutory regulation or exceeds the permitted use, you will need to obtain permission directly from the copyright holder. To view a copy of this licence, visit http://creativecomm ons.org/licenses/by/4.0/.

\section{Appendix}

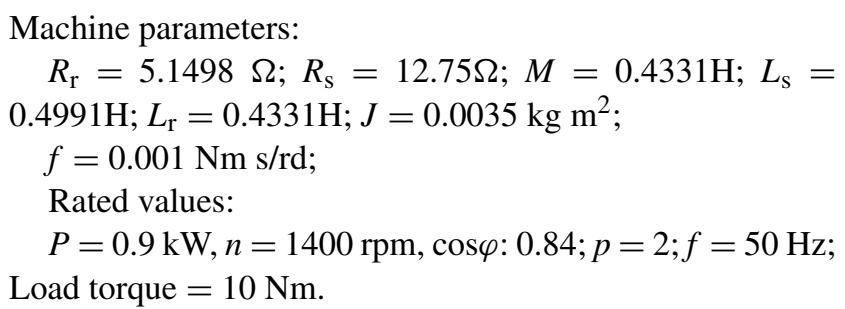

\section{References}

1. Casadei D, Profumo F, Serra G, Tani A (2002) FOC and DTC: two viable schemes for induction motors torque control. IEEE Trans
Power Electron 17(5):779-787. https://doi.org/10.1109/TPEL.200 2.802183

2. De Doncker RW, Novotny DW (1994) The universal field oriented controller. IEEE Trans Ind Appl 30(1):92-100. https://doi.org/10. $1109 / 28.273626$

3. Abu-Rub H, Schmirgel H, Holtz J (2006) Sensorless control of induction motors for maximum steady-state torque and fast dynamics at field weakening. In: Conference record of the 2006 ieee industry applications conference forty-first ias annual meeting, vol 1. pp 96-103. https://doi.org/10.1109/ias.2006.256490

4. Lascu C, Trzynadlowski AM (2004) Combining the principles of sliding mode, direct torque control, and space-vector modulation in a high-performance sensorless AC drive. IEEE Trans Ind Appl 40(1):170-177. https://doi.org/10.1109/TIA.2003.821667

5. Zaimeddine R, Undeland T (2010) DTC control schemes for induction motor fed by three-level NPC-VSI using space vector modulation. In: SPEEDAM 2010. IEEE, pp 966-971. https://doi. org/10.1109/speedam.2010.5545036

6. West NT, Lorenz RD (2007) Implementation and evaluation of a stator and rotor flux linkage-based dead-beat, direct torque control of induction machines at the operational voltage limits. In: 2007 Industry applications annual meeting. IEEE, pp 690-695. https:// doi.org/10.1109/IAS.2007.109

7. Vasudevan M, Arumugam R, Paramasivam S (2006) Development of torque and flux ripple minimization algorithm for direct torque control of induction motor drive. Electr Eng 89(1):41-51. https:// doi.org/10.1007/s00202-005-0319-x

8. Harnefors L, Nee H-P (1998) Model-based current control of AC machines using the internal model control method. IEEE Trans Ind Appl 34(1):133-141. https://doi.org/10.1109/28.658735

9. Matic PR, Blanusa BD, Vukosavic SN (2003) A novel direct torque and flux control algorithm for the induction motor drive. In: IEEE international electric machines and drives conference, 2003, IEMDC'03, vol 2. IEEE, pp 965-970. https://doi.org/10.11 09/iemdc.2003.1210351

10. Hoang L-H (1999) Comparison of field-oriented control and direct torque control for induction motor drives. In: 34th IAS Annual Meeting (Cat. No.99CH36370) on conference record of the 1999 IEEE industry applications conference, vol 2. IEEE, pp 1245-1252. https://doi.org/10.1109/ias.1999.801662

11. Telford D, Dunnigan MW, Williams BW (2000) A comparison of vector control and direct torque control of an induction machine. In: Conference proceedings (Cat. No.00CH37018) on IEEE 31st annual power electronics specialists conference, vol 1. IEEE, pp 421-426. https://doi.org/10.1109/PESC.2000.878893

12. Vaez-Zadeh S, Jalali E (2007) Combined vector control and direct torque control method for high performance induction motor drives. Energy Convers Manag 48(12):3095-3101. https://doi.org/ 10.1016/j.enconman.2007.05.010

13. Gonzalez-Avalos G, Padilla JA (2018) Quasi-steady-state model of a class of nonlinear singularly perturbed system in a bond graph approach. Electr Eng 100(1):293-302. https://doi.org/10.1007/s00 202-016-0507-X

14. Guo Y, Scherer CW (2018) Robust gain-scheduled controller design with a hierarchical structure. IFAC-PapersOnLine. 51(25):228-233. https://doi.org/10.1016/j.ifacol.2018.11.110

15. Khamari D, Makouf A, Drid S (2011) Control of induction motor using polytopic LPV models. In: International conference on communications, computing and control applications (CCCA). IEEE, pp 1-5. https://doi.org/10.1109/ccca.2011.6031401

16. Abdessalem DK, Makouf, Said D (2013) Linear parameter varying induction motor control with two-degree-of freedom controller. In: 4th International conference on power engineering, energy and electrical drives. IEEE, pp 1748-1752. https://doi.org/10.11 09/powereng.2013.6635882 
17. Khamari D, Makouf A, Drid S, Chrifi-Alaoui L (2013) High performance of self scheduled linear parameter varying control with flux observer of induction motor. J Electr Eng Technol 8(5):1202-1211. https://doi.org/10.5370/JEET.2013.8.5.1202

18. Khamari D, Benlaloui I, Ouchen S, et al (2019) LPV induction motor control with MRAS speed estimation. In: 8th international conference on systems and control (ICSC). IEEE, pp 460-464. https://doi.org/10.1109/icsc47195.2019.8950563

19. Rezaei H, Khosrowjerdi MJ (2017) A polytopic LPV approach to active fault tolerant control system design for three-phase induction motors. Int J Control 90(10):2297-2315. https://doi.org/10.1080/0 0207179.2016.1244730

20. Silva JA, Moreira MV, Basilio JC, Rolim LGB (2010) H $\infty$ design of rotor flux-oriented current-controlled induction motor drives: speed control, noise attenuation and stability robustness. IET Control Theory Appl 4(11):2491-2505. https://doi.org/10.1049/iet-cta. 2009.0377

21. Benlaloui I, Drid S, Chrifi-Alaoui L, Ouriagli M (2015) Implementation of a new MRAS speed sensorless vector control of induction machine. IEEE Trans Energy Convers 30(2):588-595. https://doi. org/10.1109/TEC.2014.2366473

22. Benlaloui I, Drid S, Khamari D, Chrifi-Alaoui L, Marhic B, Ouriagli M (2016) Analysis and design of rotor MRAS speed sensorless with a novel approach. In: 17th international conference on sciences and techniques of automatic control and computer engineering (STA). IEEE, pp 73-77. https://doi.org/10.1109/sta.2016. 7952016
23. Benlaloui I, KHEMIS A, Khamari D, DRID S, Chrifi-Alaoui L, Ouriagli M (2019) New online three phases stator resistances estimation for stator induction machine fault diagnosis. In: International conference on control, automation and diagnosis (ICCAD). IEEE, pp 1-6. https://doi.org/10.1109/iccad46983.2019.9037881

24. Benlaloui I, Khamari D, Khemis A, Drid S, Chrifi-Alaoui L, Ouriagli M (2019) MRAS type-2 fuzzy logic observer and controller for robust speed sensorless induction motor. In: International conference on control, automation and diagnosis (ICCAD). IEEE, pp 1-7. https://doi.org/10.1109/iccad46983.2019.9037880

25. Hayashi T, Fujii Y, Fujikawa K, Sekiguchi T (2000) Realization of instantaneous torque control of an induction motor considering secondary flux as a parameter. IEEJ Trans Ind Appl 120(7):862-869. https://doi.org/10.1541/ieejias.120.862

Publisher's Note Springer Nature remains neutral with regard to jurisdictional claims in published maps and institutional affiliations. 